\title{
Salinity Effects on Root Growth and Senescence in Tomato and the Consequences for Severity of Phytophthora Root Rot Infection
}

\author{
S.S. Snapp ${ }^{1}$ and C. Shennan \\ Vegetable Crops Department, University of California, Davis, CA 95616 \\ Additional index words. root turnover, root death, disease, salt stress, Lycopersicon esculentum, Phytophthora parasitica
}

\begin{abstract}
Roots respond first to edaphic stresses, yet little is known about root response to stress in mature, soil-grown plants. We investigated the effects of salinity and phytophthora root rot on root growth and senescence in tomato (Lycopersicon esculentum Mill.). Using minirhizotron- and rhizotron-based methodologies, we quantified intraspecific differences in root-system response to salinity and inoculation. Genotype susceptibility to salt-induced disease was related to root vulnerability to salt. 'UC82B' was vulnerable to infection by Phytophthora parasitica when subjected to salt stress and produced thinner roots and $\approx \mathbf{5 0 \%}$ higher root-senescence rates compared to the phytophthora root rot-resistant 'CX8303'. Root growth at the peripheral regions of the ' $\mathrm{CX8303'}$ ' root system was inhibited by salinity, but otherwise root dynamics were not affected by salinity or inoculation. Overall, roots from the central root system and roots from the periphery responded differently to salt stress. Monitoring the diameters of new initiated roots indicated the vulnerability of a stressed root system to disease and early senescence.
\end{abstract}

Adding salts to the root media for better tomato fruit quality has been advocated recently (Mizrahi et al., 1988). Tomato shoot and fruit physiological responses to salinity have been documented extensively (Cruz et al., 1990; Mitchell et al., 1991; Mizrahi et al., 1988; Niedziela et al., 1993). Yet, the effects of salt stress on below-ground processes and increased vulnerability to soil-borne pathogens remain fairly uncharacterized in tomato (Swiecki and MacDonald, 1991). Salinity can induce susceptibility to soil-borne disease organisms and can greatly enhance disease severity in many crop species (Blaker and MacDonald, 1986; El-Abyad et al., 1988; Snapp et al., 1991; Swiecki and MacDonald, 1991). Salts have also reduced disease incidence in celery and pineapple (Anderson, 1951; Schneider, 1985). Salinity effects on root growth and senescence may be related to the enhancement of root disease. Salinity reduced net root growth in field-grown tomato and citrus, a result that was correlated with severe phytophthora root rot in susceptible genotypes (Blaker and MacDonald, 1986; Snapp et al., 1991).

Limited knowledge exists on the effects of salinity on root growth and senescence rates of soil-grown crop plants. Salinity reduced root length density (RLD) of tomato and peanut late in the growing season (Chavan and Karadge, 1980; Snapp et al., 1991). Salinity enhanced initial root growth in sorghum and Rhodes grass (Gerard, 1978; Waisel, 1985) and inhibited it in citrus and tomato (Swiecki and MacDonald, 1991; Zekri and Parsons, 1990). The effects of soil-water deficit on root turnover rates are expected to be similar to those of salinity. Compared to well-watered controls, moderate drought greatly increased root growth and senescence in soybean plants (Huck et al., 1987). Yet, root senescence was almost nil under drought stress in peanuts and clover (Meisner and Karnok, 1992; Pearson and Jacobs, 1985). Major genotypic differ-

Received for publication 5 April 1993. Accepted for publication 14 June 1993. We thank the California Tomato Research Institute for providing support; A. Lauchli, J. Lynch, J.D. MacDonald, J. Richards, and A.H.C van Bruggen for thoughtful advice; and the many people who assisted in difficult aspects of this work, such as monitoring roots on hot summer days.The cost of publishing this paper was defrayed in part by the payment of page charges. Under postal regulations, this paper therefore must be hereby marked advertisement solely to indicate this fact. ${ }^{1}$ Present address: Dept. of Horticulture, Pennsylvania State Univ., University Park, PA 16803 ences may explain why some studies find large stress-induced reductions in root growth and others find small or undetectable reductions. Unfortunately, genotypic effects on root response to stress are difficult to assess. The plasticity of root response and the heterogeneous nature of soil result in high genotype $\times$ environmental interactions (Zobel, 1991). A preliminary study using a homogeneous soil mix and extensive root monitoring suggested that moderate salinity enhanced root death in one tomato genotype but not in another (Snapp and Shennan, 1992).

In this study, we investigated salinity effects on root dynamics and phytophthora root rot in two tomato cultivars with different phytophthora root rot susceptibility. We quantified root-system growth and senescence using minirhizotron access tubes, rhizotron windows, and soil core techniques to determine the relationship of root dynamics to salt stress tolerance and salt-induced disease.

\section{Materials and Methods}

Experimental design. We used the tomato cultivars UC82B, which is susceptible to phytophthora root rot, and CX8303, which is moderately resistant (Blaker and Hewitt, 1987). Treatments included two salinity levels and the presence and absence of Phytophthora parasitica inoculum. Experimental design was a randomized complete block, with five replications of each salinity $\times$ cultivar $\times$ inoculum combination.

Plant growth conditions. Plants were grown in large-volume containers, each with four compartments $50 \times 50 \times 90 \mathrm{~cm}$ deep designed to allow roots to be monitored via minirhizotron access tubes and rhizotron windows (Snapp and Shennan, 1992). Minirhizotron access tubes consisted of plexiglass tubes installed in pairs horizontally at 10 to 15,30 to 35,50 to 55 , and 70 to $75 \mathrm{~cm}$. One $65 \times 25-\mathrm{cm}$ plexiglass viewing window was installed per compartment, and transparencies were placed on the window to cover the 10 to $37-\mathrm{cm}$ and 40 to $67-\mathrm{cm}$ depths. Uniform seedlings of 'UC82B' and 'CX8303' were selected and transplanted on 17 June 1991 into the containers installed in a lathe house at the field station of the Vegetable Crops Dept., Univ. of California, Davis.

Plants were maintained in a 2 sand : 1 soil medium with a modified Hoagland's nutrient solution applied daily via a dripirrigation system. Salinity treatments were initiated 30 days after 
transplanting (DAT) by adding $3 \mathrm{~mm} \mathrm{NaCl}$ or $75 \mathrm{~mm}$ salts $(4 \mathrm{NaCl}$ $: 1 \mathrm{CaCl}_{2}$ ) to the nutrient solution. Inoculum was added 65 and 75 DAT, using a rate of $200 \mathrm{ml}$ zoospore solution per plant (inoculum concentration was $1.7 \times 10^{5}$ zoospores $/ \mathrm{ml}$ and $2.0 \times 10^{5}$ zoospores/ $\mathrm{ml}$ for 65 and 75 DAT, respectively). The Phytophthora parasitica isolate was provided by F. Workneh (Plant Pathology Dept., Univ. of California, Davis). Zoospores were produced and salt tolerance of the isolate was determined as described by Bouchibi et al. (1990). Zoospore motility and encystment rates were unaffected by the salinity levels used in this experiment (data not shown).

A root periscope (JRD Merrill Specialty Equipment, Logan, Utah) was used at 10-day intervals to observe root counts via minirhizotron access tubes. The same 15 viewing areas were monitored for each tube over the growing season by stopping at 5$\mathrm{cm}$ intervals along the tube and rotating the periscope to view three images spanning $270^{\circ}$ at each location. The location of viewing areas with respect to the central root axis (directly under the shoot) was noted, and roots were counted from either central viewing areas or peripheral viewing areas. Central roots were counted from seven viewing areas in the central $10 \mathrm{~cm}$ of the tube, and peripheral roots were counted from eight viewing areas on either side of the center. Estimates of root growth and death rates were derived from changes in root counts. Consecutive root counts were compared for each observation area and the net negative, positive, or zero change in root counts was calculated for each 10-day observation period.

Root growth and death measurements at rhizotron windows were made by a root-mapping technique described previously (Snapp and Shennan, 1992). All new root growth and roots that had disintegrated since the last map were traced using different colored permanent marking pens at 7-day intervals and at two depths (10 to $37 \mathrm{~cm}$ and 40 to $67 \mathrm{~cm}$ ). Root length was traced with a planimeter, where length associated with disintegrated roots vs. new root growth was recorded separately using the color-coded tracings. Net root growth at the rhizotron is the most appropriate measure to compare to RLD data, which is affected by root death as well as root growth rate. Net root growth was calculated by subtracting root death from root growth values. At the last three observation dates $(85,92$, and 99 DAT), root diameters were measured using $\mathrm{a} \times 10$ hand lens for a randomly selected subsample of ten roots visible at the rhizotron window. Root diameters were measured only for roots $<2 \mathrm{~mm}$ in diameter, excluding the few large-diameter adventitious roots that might have increased root diameter variability considerably (Atkinson, 1985).

At the end of the experiment, above-ground biomass was harvested and fruit were separated from the rest of the shoots. Fresh weights of fruit and vegetative matter were measured, plant material was oven-dried at $60 \mathrm{C}$ until no change in dry weight occurred, and dry weights were determined. Soil cores $(10 \mathrm{~cm}$ in diameter) were extracted on either side of the plant and subsamples were taken from the 0 to $18 \mathrm{~cm}, 18$ to $36 \mathrm{~cm}$, and 36 to $90 \mathrm{~cm}$ depths (root distribution was uniform over the 36 to $90 \mathrm{~cm}$ depth in a previous experiment, Snapp and Shennan, 1992). Root length density of soil samples was determined after wet-sieving using a modified Tennant's procedure (Tennant, 1975). Roots $>2 \mathrm{~mm}$ in diameter were removed and root samples for determining RLD were then dried and weighed to calculate specific root length (SRL). Inorganic ion and salinity levels were determined for bulked soil samples from different depths and results (Table 1). Soil characteristics were determined by the DANR analytical laboratory, Univ. of California, Davis, as described previously (Snapp and Shennan, 1992). Horizontal salinity distribution at the container surface was found to be homogenous using a soil conductivity probe (model SCT-10; Martek Instruments, Irvine, Calif.) (unpublished data). After the soil cores for the soil characteristics were removed, the central root system was extracted by saturating the soil, loosening soil around the central axes, and pulling the roots up. The central taproot system stayed intact and all major lateral roots were recovered in most cases. Root systems were washed and visually scored for Phytophthora parasitica infection. The following scale was used, based on percentage of root system covered with lesions: $0=0$ to $20 \%, 1=21$ to $40 \%, 2=41$ to $60 \%, 3=61$ to $80 \%$, and 4 $=81$ to $100 \%$ lesion coverage. Phytophthora parasitica was consistently isolated from root lesion selections placed on a selective medium (Kannwischer and Mitchell, 1978), while colonies of Phytophthora parasitica morphology were never observed from randomly selected pieces of unblemished root tissue (Snapp et al., 1991).

Statistical analysis. Data from the container experiment were analyzed as follows:

1) Repeated measures of analyses of variance (RepANOVAs) were conducted on root counts of the periphery and center, with time as the repeated-measures variable (Abacus Concepts, 1989). Data were averaged across depth as there were no significant depth $\times$ treatment interactions.

2) RepANOVAs were conducted separately on root-count increases and decreases for each cultivar, with time as the repeated-measures variable.

3) A three-way ANOVA was conducted on root diameters, shoot and fruit biomass dry weights, RLD data (a separate ANOVA was conducted for each depth), and rot-severity ratings. All data were checked for normality by plotting residuals and predicted values. Note that data from a field experiment with similar salinity, inoculum, and cultivar treatments were included in Tables 2 and 3 for comparison purposes. The field experiment was reported on previously (Snapp and Shennan, 1992); however, our study includes previously unreported inoculated 'CX8303' treatments and a new analysis using a three-way ANOVA and a split-split-plot model.

Table 1. Characteristics of soil in containers irrigated with low (3 mM) and moderately high (75 mM) saline nutrient solution, at two soil depths. SE of the means are in parentheses.

\begin{tabular}{|c|c|c|c|c|}
\hline \multirow{2}{*}{$\begin{array}{l}\text { Soil } \\
\text { characteristic }\end{array}$} & \multicolumn{2}{|c|}{ Low salinity } & \multicolumn{2}{|c|}{ Moderately high salinity } \\
\hline & $0-36 \mathrm{~cm}$ & $36-90 \mathrm{~cm}$ & $0-36 \mathrm{~cm}$ & $36-90 \mathrm{~cm}$ \\
\hline $\mathrm{EC}^{\mathrm{Z}}\left(\mathrm{dS} \cdot \mathrm{m}^{-1}\right)$ & $1.41(0.15)$ & $2.24(0.08)$ & $3.39(0.26)$ & $5.56(0.27)$ \\
\hline $\mathrm{Na}(\mathrm{meq})$ & $8.03(0.42)$ & $9.60(0.31)$ & $19.65(1.87)$ & $32.77(2.61)$ \\
\hline $\mathrm{Cl}$ (meq) & $3.90(0.44)$ & $6.67(0.38)$ & $20.30(2.12)$ & $28.31(5.66)$ \\
\hline $\mathrm{N}(\mathrm{ppm})$ & $22.17(0.45)$ & $32.07(0.18)$ & $27.95(1.03)$ & $35.80(1.41)$ \\
\hline $\mathrm{P}(\mathrm{ppm})$ & $261.68(10.4)$ & $242.00(10.0)$ & $287.50(12.4)$ & $162.46(17.4)$ \\
\hline $\mathrm{K}(\mathrm{meq})$ & $284.70(17.0)$ & $366.65(14.6)$ & $213.50(7.42)$ & $281.50(10.3)$ \\
\hline
\end{tabular}

$\overline{\mathrm{z}} \mathrm{EC}=$ electrical conductivity. 
Table 2. Salinity (S) and inoculum (I) effects on phytophthora root rot severity and root length density (RLD) of 'UC82B' (root-rot susceptible) and 'CX8303' (root-rot resistant) at the end of the container experiment, at three depths ( 0 to 18, 18 to 36, and 36 to $90 \mathrm{~cm}$ ). For comparison purposes, data from a similar field experiment are reported for two depths (data from the uninoculated field experiment published previously, Snapp and Shennan, 1992). Low and high salinity treatments were 0 and $150 \mathrm{mM}$ salts $\left(4 \mathrm{NaCl}: 1 \mathrm{CaCl}_{2}\right)$ added in the field experiment, and $3 \mathrm{mM} \mathrm{NaCl}$ and $75 \mathrm{mM}$ salts $\left(\mathrm{NaCl}\right.$ and $\left.\mathrm{CaCl}_{2}\right)$ in the container experiment.

\begin{tabular}{|c|c|c|c|c|c|c|c|}
\hline \multirow[b]{3}{*}{$\mathrm{S} / \mathrm{I}$} & \multicolumn{3}{|c|}{ Field experiment } & \multicolumn{4}{|c|}{ Container experiment } \\
\hline & \multirow{2}{*}{$\begin{array}{c}\text { Rot severity } \\
\text { rating }^{z}\end{array}$} & \multicolumn{2}{|c|}{$\operatorname{RLD}\left(\mathrm{cm} \cdot \mathrm{cm}^{-3}\right)$} & \multirow{2}{*}{$\begin{array}{c}\text { Rot severity } \\
\text { rating }\end{array}$} & \multicolumn{3}{|c|}{$\operatorname{RLD}\left(\mathrm{cm} \cdot \mathrm{cm}^{-3}\right)$} \\
\hline & & $0-25 \mathrm{~cm}$ & $25-50 \mathrm{~cm}$ & & $0-18 \mathrm{~cm}$ & $18-36 \mathrm{~cm}$ & $36-90 \mathrm{~cm}$ \\
\hline \multicolumn{8}{|c|}{$U C 82 B$} \\
\hline Low / - & 0.3 & 1.15 & 0.64 & 0.0 & 0.78 & 0.73 & 0.71 \\
\hline Low / + & 0.5 & 1.35 & 0.43 & 0.4 & 0.79 & 0.65 & 0.67 \\
\hline High / - & 0.6 & 0.59 & 0.43 & 0.0 & 1.05 & 0.71 & 0.20 \\
\hline High / + & 2.3 & 0.61 & 0.29 & 1.9 & 1.01 & 0.70 & 0.51 \\
\hline \multicolumn{8}{|c|}{ CX8303 } \\
\hline Low / - & 0.2 & 0.70 & 0.50 & 0.0 & 0.73 & 0.80 & 0.68 \\
\hline Low / + & 0.7 & 1.09 & 0.59 & 0.1 & 0.90 & 1.58 & 0.71 \\
\hline High / - & 0.5 & 0.93 & 0.57 & 0.0 & 0.98 & 1.11 & 0.77 \\
\hline High / + & 1.2 & 1.24 & 0.86 & 0.9 & 1.03 & 0.77 & 0.65 \\
\hline \multicolumn{8}{|l|}{ Significance } \\
\hline $\mathrm{S}$ & $* * *$ & $*$ & NS & $* * *$ & NS & NS & $*$ \\
\hline I & $*$ & NS & NS & $* * *$ & NS & NS & NS \\
\hline Cultivar (C) & NS & NS & $*$ & $*$ & NS & $* *$ & $*$ \\
\hline $\mathrm{S} \times \mathrm{I}$ & $*$ & NS & NS & $* * *$ & NS & NS & NS \\
\hline $\mathrm{S} \times \mathrm{C}$ & $*$ & $* *$ & $*$ & NS & NS & NS & NS \\
\hline $\mathrm{I} \times \mathrm{C}$ & $*$ & NS & $*$ & $*$ & NS & NS & NS \\
\hline $\mathrm{S} \times \mathrm{I} \times \mathrm{C}$ & NS & NS & NS & NS & NS & NS & NS \\
\hline
\end{tabular}

Ns,*,**,****Nonsignificant or significant at $P \leq 0.05,0.01$, and 0.001 , respectively, by analysis of variance.

${ }^{\mathrm{z}}$ Rated on a scale of $0=$ low, $4=$ high.

\section{Results and Discussion}

Salinity substantially increased tomato susceptibility to Phytophthora parasitica (Table 2), a result in agreement with Swiecki and MacDonald's findings (1991). Salinity increased lesion coverage of the central root system in both tomato genotypes, but coverage was more extensive in 'UC82B' than in 'CX8303'. This result is consistent with reports that ' $\mathrm{CX} 8303$ ' is moderately resistant to phytophthora root rot (Blaker and Hewitt, 1987). Earlier studies indicated that the root-system response to salinity could help explain susceptibility to salt-enhanced phytophthora root rot in citrus trees (Blaker and MacDonald, 1986) and tomato (Snapp et al., 1991). Our RLD data supported this hypothesis, as net root growth was maintained under salt stress in the resistant cultivar and was suppressed in the susceptible cultivar (Table 2).

Initial analysis of root-count data from minirhizotron observations in the container experiment did not support RLD findings. Root-count data were analyzed using an average value for each depth, and the cultivars' response to salinity seemed similar (data not shown). Further analysis, however, showed root response to salinity was markedly influenced by genotype when root location relative to the central root axis was considered. Root growth in 'UC82B' was inhibited by salinity throughout the root system, whereas root growth in 'CX8303' was only inhibited at the peripheral region of the root system (Fig. $1 \mathrm{~A}$ and B). Considering that RLDs were from soil cores taken near the taproot, RLDs should be compared to root-count data from the central root system. The central root system comparison showed that salinity reduced root growth in 'UC82B' in almost all cases, but did not consistently reduce root growth in 'CX8303' (Fig. 1A and Table 2). 'CX8303' root growth is markedly reduced by salinity at the periphery (Fig. 1B). Salinity did not vary horizontally, a result suggesting that root responsiveness did. Differences in root response to salinity near the central tap root compared to root response at the periphery may be due to the growth processes involved. The architecture of a tomato root system is a modified taproot, in which initiation rates of main laterals and secondary roots influence the root number near the center of the root system, whereas lateral root-elongation rate as well as initiation of secondary roots determine root observations at the periphery (S.S. Snapp, personal observations). Further research is needed to determine if lateral root initiation is more tolerant to salt stress in 'CX8303' than in 'UC82B'. Interestingly, Waisel and Breckle (1987) demonstrated that initiation of lateral roots in radish was relatively tolerant to salinity, whereas elongation of lateral roots was a saltsensitive process.

Different growing conditions make comparisons difficult, but salinity reduced shoot and fruit biomass in the container-grown plants in a similar manner to field-grown plants in almost all cases (Table 3). Shoot growth of 'CX8303' was, surprisingly, little influenced by salinity in the field, whereas container-grown 'CX8303' had large biomass reductions under salt treatment. Compensatory growth of 'CX8303' roots in localized, low-salt regions could occur in the heterogeneous field environment, but not in the homogeneous saline soil of containers. This may partially explain the moderate effect of salinity on 'CX8303' under field conditions. Compensatory tomato root growth in a differentially salinized environment has been previously demonstrated (Papadopolus and Rendig, 1983). Overall, salinity induced a fairly consistent $30 \%$ reduction in vegetative and fruit biomass production of field- and container-grown plants (Table 3). Other studies of tomato-growth responses at similar salinity levels have also shown $\approx 30 \%$ reduction in biomass (Cruz et al., 1990; Shannon et al., 1987). Inoculation reduced fruit production in the field but had 

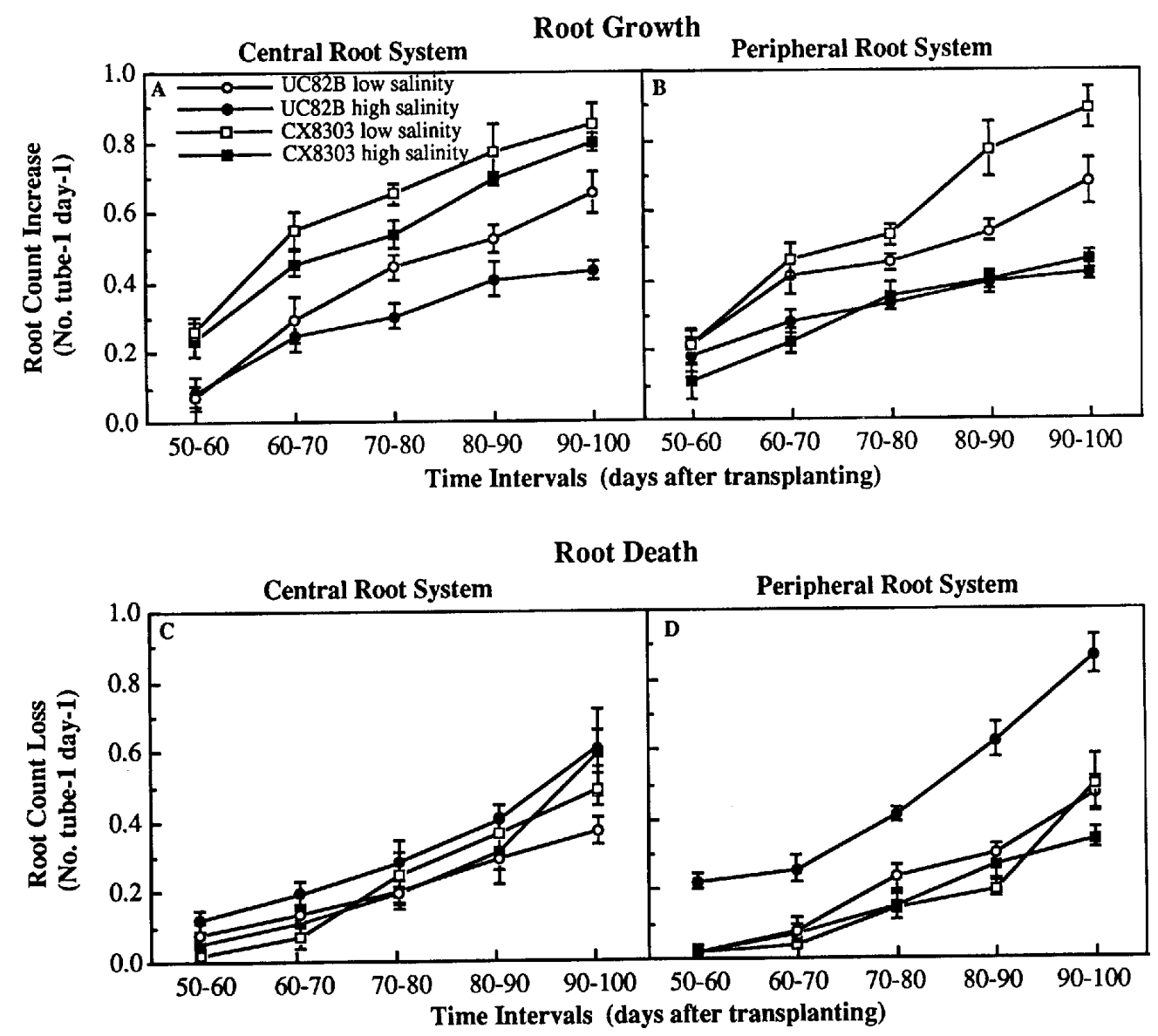

Fig. 1. Salinity, cultivar, and root location effects on minirhizotron root-count observations. Root counts presented are those gained (A) and lost (C) over 10-day observation periods, calculated on a per observation area basis, and averaged for the center regions of each observation tube. Root counts for peripheral regions are presented in $\mathbf{B}$ (root counts gained) and $\mathbf{D}$ (root counts lost). Data presented are means and error bars represent SES.

Table 3. Salinity (S), cultivar (C), and inoculum (I) effects on total above-ground dry weight, fruit dry weight, and fruit number per plant for 'UC82B' and 'CX8303' at the end of the container experiment. For comparison purposes, data from a similar field experiment are reported (data from the uninoculated field experiment published previously, Snapp and Shennan, 1992). Low and high salinity treatments were $0 \mathrm{mM} \mathrm{NaCl}$ and $150 \mathrm{mM}$ salts $\left(4 \mathrm{NaCl}: 1 \mathrm{CaCl}_{2}\right)$ added in the field experiment, and $3 \mathrm{mM} \mathrm{NaCl}$ and $75 \mathrm{~mm}$ salts $\left(4 \mathrm{NaCl}: 1 \mathrm{CaCl}_{2}\right)$ in the container experiment.

\begin{tabular}{|c|c|c|c|c|c|}
\hline \multirow[b]{2}{*}{$\mathrm{S} / \mathrm{I}$} & \multicolumn{2}{|c|}{ Field experiment } & \multicolumn{3}{|c|}{ Container experiment } \\
\hline & $\begin{array}{c}\text { Shoot } \\
\text { (g/plant) }\end{array}$ & $\begin{array}{c}\text { Fruit } \\
\text { (g/plant) }\end{array}$ & $\begin{array}{c}\text { Shoot } \\
\text { (g/plant) }\end{array}$ & $\begin{array}{c}\text { Fruit } \\
\text { (g/plant) }\end{array}$ & $\begin{array}{c}\text { Fruit } \\
\text { (no./plant) }\end{array}$ \\
\hline \multicolumn{6}{|c|}{$U C 82 B$} \\
\hline Low / - & 318.5 & 151.1 & 180.5 & 68.5 & 46.2 \\
\hline Low / + & 286.0 & 125.0 & 183.9 & 53.0 & 35.4 \\
\hline High / - & 197.1 & 76.9 & 109.2 & 33.5 & 26.0 \\
\hline High / + & 169.9 & 66.2 & 109.8 & 40.8 & 29.0 \\
\hline \multicolumn{6}{|c|}{ CX8303 } \\
\hline Low / - & 346.8 & 146.0 & 179.9 & 74.0 & 48.4 \\
\hline Low / + & 344.1 & 121.9 & 152.4 & 61.2 & 48.8 \\
\hline High / - & 288.9 & 59.6 & 118.6 & 54.9 & 38.0 \\
\hline High / + & 308.8 & 55.6 & 113.8 & 45.0 & 27.6 \\
\hline \multicolumn{6}{|l|}{ Significance } \\
\hline $\mathrm{S}$ & $* *$ & $*$ & $* * *$ & $* * *$ & $* * *$ \\
\hline I & NS & $*$ & NS & NS & NS \\
\hline $\mathrm{C}$ & $* * *$ & NS & NS & $* *$ & NS \\
\hline $\mathrm{S} \times \mathrm{I}$ & NS & NS & NS & NS & NS \\
\hline $\mathrm{S} \times \mathrm{C}$ & $*$ & NS & NS & NS & NS \\
\hline $\mathrm{I} \times \mathrm{C}$ & NS & NS & NS & NS & NS \\
\hline $\mathrm{S} \times \mathrm{I} \times \mathrm{C}$ & NS & NS & NS & NS & NS \\
\hline
\end{tabular}

$\overline{\mathrm{NS}, *, * *, * * *}$ Nonsignificant or significant at $P \leq 0.05,0.01$, and 0.001 , respectively. 
Table 4. Salinity (S) and cultivar (C) effects on net root growth, root death, and root diameters measured at rhizotron windows on the last three observation dates [85, 92, and 99 days after transplanting (DAT)]. Salinity treatments consisted of low $(3 \mathrm{mM} \mathrm{NaCl})$ and high $(75 \mathrm{mM} \mathrm{salts,} 4 \mathrm{NaCl}$ : $1 \mathrm{CaCl}_{2}$ ) levels applied to ' $\mathrm{UC} 82 \mathrm{~B}$ ' and 'CX8303'. Inoculum effects were not significant and data are averaged across plus and minus inoculation by Phytophthora parasitica.

\begin{tabular}{|c|c|c|c|c|c|c|}
\hline \multirow[b]{2}{*}{ Time $(\mathrm{T})$} & \multicolumn{3}{|c|}{ 10-37 cm Deep } & \multicolumn{3}{|c|}{ 40-67 cm Deep } \\
\hline & $\begin{array}{l}\text { Net root } \\
\text { growth } \\
\left(\mathrm{cm} \cdot \mathrm{cm}^{-2}\right)\end{array}$ & $\begin{array}{l}\text { Root death } \\
\left(\mathrm{cm} \cdot \mathrm{cm}^{-2}\right)\end{array}$ & $\begin{array}{c}\text { Root diam } \\
(\mathrm{mm})\end{array}$ & $\begin{array}{l}\text { Net root } \\
\text { growth } \\
\left(\mathrm{cm} \cdot \mathrm{cm}^{-2}\right)\end{array}$ & $\begin{array}{c}\text { Root death } \\
\left(\mathrm{cm} \cdot \mathrm{cm}^{-2}\right)\end{array}$ & $\begin{array}{l}\text { Root diam } \\
(\mathrm{mm})\end{array}$ \\
\hline \multicolumn{7}{|c|}{ UC82B-Low $S$} \\
\hline 85 DAT & 0.2 & 0.2 & 0.6 & 0.2 & 0.1 & 0.8 \\
\hline $92 \mathrm{DAT}$ & 0.2 & 0.2 & 0.7 & 0.2 & 0.1 & 0.9 \\
\hline 99 DAT & 0.1 & 0.2 & 0.9 & 0.2 & 0.1 & 0.9 \\
\hline \multicolumn{7}{|c|}{ UC82B-High $S$} \\
\hline $85 \mathrm{DAT}$ & 0.2 & 0.2 & 0.5 & 0.2 & 0.1 & 0.6 \\
\hline $92 \mathrm{DAT}$ & 0.1 & 0.2 & 0.7 & 0.1 & 0.2 & 0.7 \\
\hline 99 DAT & 0.1 & 0.3 & 0.5 & 0.0 & 0.2 & 0.6 \\
\hline \multicolumn{7}{|c|}{ CX8303-Low $S$} \\
\hline 85 DAT & 0.6 & 0.2 & 0.4 & 0.4 & 0.1 & 0.5 \\
\hline $92 \mathrm{DAT}$ & 0.5 & 0.2 & 0.6 & 0.5 & 0.1 & 0.6 \\
\hline $99 \mathrm{DAT}$ & 0.5 & 0.3 & 0.6 & 0.5 & 0.1 & 0.7 \\
\hline \multicolumn{7}{|c|}{ CX8303-High S } \\
\hline 85 DAT & 0.2 & 0.2 & 0.7 & 0.2 & 0.1 & 0.7 \\
\hline 92 DAT & 0.2 & 0.2 & 0.7 & 0.2 & 0.1 & 0.7 \\
\hline 99 DAT & 0.2 & 0.2 & 0.7 & 0.2 & 0.1 & 0.7 \\
\hline \multicolumn{7}{|c|}{ Significance } \\
\hline $\mathrm{T}$ & $* * *$ & $* * *$ & NS & $* *$ & $* * *$ & NS \\
\hline $\mathrm{S}$ & $*$ & NS & NS & NS & NS & $*$ \\
\hline $\mathrm{C}$ & $*$ & NS & NS & $*$ & NS & NS \\
\hline $\mathrm{T} \times \mathrm{S}$ & $* *$ & NS & NS & $* *$ & NS & NS \\
\hline $\mathrm{T} \times \mathrm{C}$ & $* *$ & NS & NS & $* *$ & NS & NS \\
\hline $\mathrm{S} \times \mathrm{C}$ & NS & $*$ & $* * *$ & $*$ & NS & $* *$ \\
\hline $\mathrm{T} \times \mathrm{S} \times \mathrm{C}$ & $* *$ & NS & NS & $* *$ & $*$ & NS \\
\hline
\end{tabular}

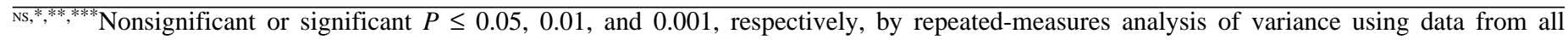
measurement dates.

little effect on above-ground growth in containers, which may be due to late application of Phytophthora parasitica in the containers and the relatively low disease levels (Table 3). In keeping with our data, Swiecki and MacDonald (1991) found that older tomato plants were less susceptible to phytophthora root rot than young plants. Using drip irrigation in our experiments ensured high nutrient and water availability throughout the growing season for both field- and container-grown plants. Adequate nutrient and water levels may have ameliorated effects of salinity and phytophthora root rot infection on shoot growth and fruit production.

Thinner roots were observed in saline-treated 'UC82B', and thicker roots in saline-treated 'CX8303' (Table 4). Specific rootlength values from the lower soil depths in the container experiment indicated that salinity may reduce root diameters in ' $\mathrm{UC} 82 \mathrm{~B}$ ', although the data were highly variable (data not shown). Salt stress induces thinner cotton roots by decreasing root cell size (Kurth et al., 1986). Root elongation rate decreased and root diameters were reduced in maize seedlings exposed to low water potential (Sharp et al., 1990). Either production of thinner roots or salt-induced changes in root physiology may account for salt-enhanced phytophthora root rot infection in 'UC82B' (Table 2). Thinner roots, which have fewer cortex cells and may have a less-developed epidermis and hypodermis, possibly allow faster hyphal penetration into the root stele by Phytophthora parasitica. However, roots of low-salinity 'CX8303' were as thin as salt-stressed 'UC82B' (Table 4) without being concurrently vulnerable to infection by
Phytophthora parasitica. An earlier study suggested that resistance to infection by Phytophthora parasitica in 'CX8303' and many wild Lycopersicon species was related to slow penetration of the outer cell layers (epidermis and underlying hypodermis) in roots (Blaker and Hewitt, 1987).

Salt stress also increased root senescence in 'UC82B' at lower soil depths (Fig. 1D and Table 4). In contrast to 'UC82B', root senescence was not enhanced by salinity in 'CX8303'. These findings concur with an earlier study of salinity and root senescence in mature 'UC82B' and 'CX8303' root systems (Snapp and Shennan, 1992). High root death rates in 'UC82B' under stress could markedly reduce yields under nonirrrigated conditions. In this study, water and nutrients were not limited and the consequences of enhanced root senescence may have been ameliorated.

Inoculation did not significantly affect root senescence in either cultivar. However, senescence measurements varied greatly depending on whether rhizotron or minirhizotron was used. Further, the container-grown plants were inoculated late and had low disease severity. When data from the last observation were analyzed on an individual plant basis, 'UC82B' showed a negative correlation between root counts (minirhizotron data) and root-rot severity $\left(\mathrm{Y}=10.6-2.9 \mathrm{X}, r^{2}=0.8\right)$. The correlation was much smaller in 'CX8303' ( $\left.\mathrm{Y}=15.2-4.8 \mathrm{X}, r^{2}=0.5\right)$. With the disease severity ratings (Table 2), the data suggested that infection by Phytophthora parasitica occurred in both cultivars under saline conditions, but the rate of hyphal invasion was delayed in 'CX8303'. 
Overall, the methodologies used to examine root growth and senescence were in agreement. To make comparisons between data from minirhizotrons, rhizotrons, and soil cores, it was important to consider where the data were collected. One unusual case was 'CX8303' root growth at the rhizotron window. Under low salinity, 'CX8303' root growth was much larger than expected when compared with root count (minirhizotron) or RLD data (compare Table 4, Fig. 1b, and Table 2). A similar discrepancy between rhizotron-based observations and other root-growth measures in 'CX8303' was noted in an earlier study (Snapp and Shennan, 1992). This may be due to an edge effect. Despite the large-volume containers used, 'CX8303' may be responding to root restriction with high rates of root expansion at the container edge. In strawberries and apple trees, root proliferation at the rhizotron-soil interface is unrepresentative of root growth in soil (Atkinson, 1985). Genotypic differences in carbohydrate or hormonal status may explain why 'CX8303' proliferates at the rhizotron window but 'UC82B' does not (Fig. 1a). Rhizotron observations of cultivar differences in root senescence under different treatments were representative of minirhizotron root-count data and RLD data (Fig. $1 \mathrm{C}$ and D, Tables 2 and 4). Our results indicate that rhizotron observations are useful for documenting the relative effects of environmental stress on roots of different genotypes, but quantification of root growth from rhizotron measurements should be evaluated for artifactual problems.

\section{Conclusion}

Adding salts to the growth media enhances tomato fruit quality, but our results urge caution. Salinity in the presence of soil pathogens may have undesirable consequences, such as saltenhanced phytophthora root rot infection. We found marked intraspecific differences in tomato root-system responses to salinity and inoculation: 'UC82B' produced thin roots under salt stress and was more vulnerable than 'CX8303' to root senescence and infection by Phytophthora parasitica. Root growth at the peripheral regions of the ' $\mathrm{CX} 8303$ ' root system was inhibited by salinity; otherwise, salinity and inoculation had no effects on 'CX8303' roots. To investigate intraspecific differences in root response to stress, it was important to go beyond conventional observations of root length at different depths and to consider root system architecture.

\section{Literature Cited}

Abacus Concepts. 1989. SuperAnova. Abacus Concepts, Berkeley, Calif. Anderson, E. J. 1951. Effect of nutrient salt concentrations on infection of pineapple roots by Phytophthora cinnamomi. Phytopathology 41:2.

Atkinson, D. 1985. Spatial and temporal aspects of root distribution as indicated by the use of a root observation laboratory, p. 3-23. In: Fitter, Atkinson, Read and Usher (eds.). Ecological interactions in soil. Brit. Ecol. Soc., Blackwell, Oxford, UK. Spec. Publ. 4.

Blaker, N.S. and J.D. Hewitt. 1987. A comparison of resistance to Phytophthora parasitica in tomato. Phytopathology 77:1113-1116.

Blaker, N.S. and J.D. MacDonald. 1986. The role of salinity in the development of Phytophthora root rot of citrus. Phytopathology 76:970 975.

Bouchibi, N., A.H.C. van Bruggen and J.D. MacDonald. 1990. Effect of ion concentration and sodium:calcium ratio of a nutrient solution on Phytophthora root rot of tomato and zoospore motility and viability of Phytophthora parasitica. Phytopathology 80:1323-1336.

Chavan, P.D. and B.A. Karadge. 1980. Influence of salinity on mineral nutrition of peanut (Arachis hypogea L.). Plant Soil 54:5-13.

Cruz, V., J. Cuartero, M.C. Bolarin, and M. Romero. 1990. Evaluation of characters for ascertaining salt stress responses in Lycopersicon species. J. Amer. Soc. Hort. Sci. 115:1000-1003.

El-Abyad, M.S., H. Hindorf, and M.A. Rizk. 1988. Impact of salinity stress on soil-borne fungi of sugarbeet. Plant Soil 110:27-32.

Gerard, C.J. 1978. Root growth along plexiglass surfaces by sugarcane under different soil salinity conditions. Agron. J. 70:639-643.

Huck, M.G., G. Hoogenboom, and C.M. Peterson. 1987. Minirhizotron observation tubes: methods and applications for measuring rhizosphere dynamics. Amer. Soc. of Agron., Madison, Wis. Spec. Publ. 50. p. 109121.

Kannwischer, M.E. and D. J. Mitchell. 1978. The influence of fungicide on the epidemiology of black shank of tobacco. Phytopathology 68:17601765.

Kurth, E., G.R. Cramer, A. Lauchli, and E. Epstein. 1986. Effects of $\mathrm{NaCl}$ and $\mathrm{CaCl}_{2}$ on cell enlargement and cell production in cotton roots. Plant Physiol. 82:1102-1106.

Meisner, C.A. and K.J. Karnok. 1992. Peanut root response to drought stress. Agron. J. 84:159-165.

Mitchell , J.P., C. Shennan, S.R. Gratten, and D.M. May. 1991. Tomato fruit yields and quality under water deficit and salinity. J. Amer. Soc. Hort. Sci. 116:2215-221.

Mizrahi, Y., E. Taleisnik, V. Kagan-Zur, Y. Zohar, R. Offenbach, E. Matan, and R. Golan. 1988. A saline irrigation regime for improving tomato fruit quality without reducing yield. J. Amer. Soc. Hort. Sci. 113:202-205.

Niedziela, C.E., Jr., P.V. Nelson, D.H. Willits, and M.M. Peet. 1993. Short-term salt-shock effects on tomato fruit quality, yield, and vegetative prediction of subsequent fruit quality. J. Amer. Soc. Hort. Sci. 118:12-16.

Papadopolous, I. and V.V. Rendig. 1983. Tomato plant response to soil salinity. Agron. J. 75:696-700.

Pearson, C.J. and B.C. Jacobs. 1985. Root distribution in space and time in Trifolium subterraneum. Austral. J. Agr. Res. 36:601-614.

Schneider, R.W. 1985. Suppression of Fusarium yellows of celery with potassium, chloride, and nitrate. Phytopathology 75:40-48.

Shannon, M.C., J.W. Gronwald, and M. Tal. 1987. Effects of salinity on growth and accumulation of organic and inorganic ions in cultivated and wild tomato species. J. Amer. Soc. Hort. Sci. 112:416-423.

Sharp, R.E., T.C. Hsiao, and W.K. Silk. 1990. Growth of the maize primary root at low water potentials. II. Role of growth and deposition of hexose and potassium in osmotic adjustment. Plant Physiol. 93:13371346.

Snapp, S. and C. Shennan. 1992. Salinity effects on root growth and death dynamics of tomato, Lycopersiconesculentum Mill. New Phytol. 121:7179.

Snapp, S., C. Shennan, and A.H.C. van Bruggen. 1991. Salinity effects on severity of Phytophthora parasitica Dast. infection, inorganic ion relations and growth of Lycopersicon esculentum Mill. 'UC82B'. New Phytol. 119:275-284.

Swiecki, T.J. and J.D. MacDonald. 1991. Soil salinity enhances Phytophthora root rot of tomato but hinders asexual reproduction by Phytophthora parasitica. J. Amer. Soc. Hort. Sci. 116:471-477.

Tennant, D. 1975. A test of a modified line intersect method of estimating root length. J. Ecol. 63:995-1001.

Waisel, Y. 1985. The stimulating effects of $\mathrm{NaCl}$ on root growth of Rhodes grass (Chloris gayana). Physiol. Plant. 64:519-522.

Waisel, Y. and S.W. Breckle. 1987. Differences in responses of various radish roots to salinity. Plant Soil 104:191-194.

Zekri, M. and L.R. Parsons. 1990. Comparative effects of $\mathrm{NaCl}$ and polyethylene glycol on root distribution, growth, and stomotal conductance of sour orange seedlings. Plant Soil 129:137-143.

Zobel, R.W. 1991. Genetic control of root systems, p. 25-38. In: Waisel, Eshel and Kafkafi (eds.). Plant roots: The hidden half. Marcel Dekker, New York. 